Rev. Biol. Neotrop. 5(2): 11-22, 2008

\title{
so de Siparuna guianensis Aublet (negramina) em Bom Sucesso, município de Várzea Grande, Mato Grosso
}

\section{Carla Maria Abido Valentini}

Instituto Federal de Educação, Ciência e Tecnologia de Mato Grosso (IFMT), Campus Cuiabá, Av. Juliano Costa Marques, s/n, Bela Vista, 78.050-560, Cuiabá, Mato Grosso, Brasil; e-mail: carla.valentini@blv.ifmt.edu.br

\section{Juliane Dias de Almeida}

Programa de Pós-graduação em Agricultura Tropical da Universidade Federal de Mato Grosso, Av. Fernando Correa da Costa, s/n, Coxipó, 78.060-900, Cuiabá, Mato Grosso, Brasil

\section{Maria de fátima Barbosa Coelho}

Departamento de Ciências Vegetais da Universidade Federal Rural do Semi-Árido, BR 110, km 47, 59625-900, Presidente Costa e Silva, Mossoró, Rio Grande do Norte, Brasil

\section{Carmen Eugenia Rodríguez Ortíz}

Departamento de Botânica e Ecologia da Universidade Federal de Mato Grosso, Av. Fernando Corrêa da Costa, s/n, Coxipó,78060-900,Cuiabá, Mato Grosso, Brasil

\begin{abstract}
Resumo: Este trabalho teve como objetivo realizar um estudo acerca da espécie medicinal Siparuna guianensis Aublet (negramina), na comunidade ribeirinha de Bom Sucesso, localizada no município de Várzea Grande, Mato Grosso. Foram feitas entrevistas semiestruturadas com questões fechadas e/ou abertas. Concluiu-se que a principal forma de preparo foi a decocção das folhas, utilizada na forma de banho tópico para alívio de sintomas da gripe, tais como febre e dores no corpo, e verificou-se que este conhecimento não está sendo repassado às novas gerações do local.
\end{abstract}

Palavras-chave: Comunidade tradicional; etnobotânica; planta medicinal.

Abstract: The purpose of this research was to study the medicinal species Siparuna guianensis Aublet (negramina) in the riverside community of Bom Sucesso, a small location in the municipality of Várzea Grande, Mato Grosso. We conducted interviews using a semi-structured questionnaire containing a set of closed-ended and/or open-ended questions. We concluded that the main form of preparation was the decoction of the leaves used as a topic bath to relieve the symptoms of the flu, such as fever and body pain, and we detected that this knowledge is not being handed down to new generations.

KeY words: Traditional community; ethnobotany; medicinal plant.

\section{INTRODUÇÃo}

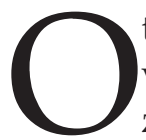
termo "populações tradicionais" vem sendo cada vez mais utilizado nos meios acadêmicos, políticos e sociais, não mais com uma conotação pejorativa, vinculada à noção de atraso e subdesenvolvimento, como ocorria há algumas décadas, mas como baluarte de um pretenso novo paradigma da modernidade: o desenvolvimento sustentável (Fleury \& Almeida, 2007).
Conforme Diegues (2003), pode-se entender o conceito de culturas tradicionais como aquelas associadas a modos de produção pré-capitalistas, ou seja, sociedades em que o trabalho ainda não se tornou uma mercadoria e em que há grande dependência dos elementos naturais e dos ciclos da natureza. Nessas sociedades, a dependência do mercado existe, porém não é total.

Ao longo das muitas gerações, tais populações acumularam conhecimentos de 
sua natureza próxima, vivenciada, desenvolvendo capacidade ímpar de interferir no ambiente de forma sustentável (Nordi et al., 2001). Assim, a diversidade biológica foi sendo mantida de forma conjunta com a diversidade cultural dessas populações.

Em função da forte influência do meio, as comunidades tradicionais apreendem a realidade e a natureza, não só com base em experiência e racionalidade, mas em valores, símbolos, crenças e mitos (Monteles \& Pinheiro, 2007).

A abordagem etnobotânica situa-se em um campo interdisciplinar que visa ampliar o diálogo entre as ciências naturais e sociais na área da botânica. Desse modo, por meio dela estudam-se conhecimentos, crenças, sentimentos e comportamentos que intermediam as interações entre as populações humanas e as plantas.

O estudo etnobotânico da espécie Siparuna guianensis, de nome popular negramina, compreende as interações estabelecidas pela população da comunidade ribeirinha de Bom Sucesso, localizada no município de Várzea Grande, Mato Grosso, ao longo de sua história e das transformações ocorridas no lugar.

Em muitos países da América, a decocção de folhas da $S$. guianensis é usada como uma bebida contra as desordens estomacais. As folhas são usadas também em compressas ou cataplasmas contra dor de cabeça e reumatismo. No Panamá e na Guiana, extratos dessa planta são usados para matar insetos daninhos. Na Guiana, suas folhas são também usadas para preparar armadilhas para peixes em decorrência de seu típico odor, que disfarça o cheiro humano. Nas vizinhanças do Suriname, a decocção feita das folhas é usada como bebida ou para banho depois do parto (Renner \& Hausner, 2005). Em um estudo na Guiana Francesa com diferentes grupos e nacionalidades (criolos, palikur, galibi, brasileiros e europeus), Vigneron et al. (2005) verificaram que as folhas de $S$. guianensis combinadas com folhas de Campomanesia spp. são ali usadas como remédio antimalária.

No Amazonas, região das Guianas, as folhas são preparadas como chá e tomadas para febre, pressão arterial alta, doenças reumáticas e cólicas (Prance, 1972; Santos \&
Peixoto, 2001). Os índios Palikur usam externamente as folhas moídas com sal para o preparo de cataplasma antiinflamatório. Os índios Wayãpi, do Amazonas, tomam o decocto das folhas e da casca do caule para calafrios, gripe e febre, administrando-o oralmente em pequenas quantidades ou principalmente na forma de banhos (Lorenzi \& Matos, 2002).

Ainda no Amazonas, os índios Tikuna comem os frutos dessa espécie para dispepsia e indigestão. Os Kubeo usam suas folhas para mordedura de serpente e fazem chá dos frutos para aliviar congestão nasal e calafrios. Os Waorani esmagam os frutos e as folhas para fazer uma mistura pungente, a qual é esfregada no rosto e na cabeça para tratar "dor de cabeça de febre", e uma infusão das folhas é empregada por eles como febrífugo. Já os índios Tacana, grupo étnico boliviano do Amazonas, fazem uso externo da decocção das folhas para gripe (Bourdy et al. 2000). Os índios Yanomami cheiram as folhas amassadas e as esfregam em suas testas e corpos para vertigem (Milliken \& Albert, 1996).

Em diversos estados brasileiros, o uso de $S$. guianensis tem sido relatado. Rodrigues et al. (2002) citaram o uso da espécie pela população de Luminárias, Minas Gerais, como tendo poderes sobrenaturais, em banho de descarrego. No mercado de Madureira, Rio de Janeiro, de acordo com relato de Arjona et al. (2007), a espécie também é vendida para esta finalidade.

Na comunidade Mumbuca, em Jalapão, no Tocantins, faz-se uso de sua infusão como analgésico (Rocha-Coelho \& Santos, 2008). Na região do Alto do Rio Grande, em Minas Gerais, emprega-se decocto ou infuso de toda a planta como antiinflamatório, carminativo, estimulante, na cefalalgia, nas gripes e resfriados, bem como de cataplasma, compressa ou banho para reumatismo (Rodrigues \& Carvalho, 2001). Souza \& Felfili (2006) também mencionaram seu uso pela população de Alto Paraíso de Goiás para tratamentos de coluna, reumatismo e artrite.

Em estudos nas comunidades rurais limítrofes à Reserva Biológica de Poço das Antas, no Rio de Janeiro, faz-se uso de seu caule como combustível. Nesses locais, o caule fornece lenha para alimentação de fogões, fornos e tachos 
para o beneficiamento de produtos agrícolas (Christo et al., 2006; Pinto Sobrinho, 2007).

No estado de Mato Grosso, foram realizados alguns estudos etnobotânicos com a espécie, nos quais é citada pelo nome vulgar de negramina. Carmona \& Guarim Neto (2001) relataram que a leste do estado, as folhas da espécie são utilizadas na forma de banho para sinusite. Souza (1992) também apontou em sua pesquisa que moradores da comunidade ribeirinha do Coxipó do Ouro utilizam essas folhas em banho para dores no corpo. No Alto Coité, em Poxoréo, as pessoas utilizam semonte, que consiste em folhas secas colocadas perto do fogo, que são posteriormente moídas e o pó é empregado em sua forma pura ou misturado ao fumo para cheirar, em uso tópico, com o intuito de curar malina, descrita como uma dor de cabeça causada pela exposição demasiada ao sol, que provoca corrimento de sangue nasal (Somavilla, 1998). No Vale do Aricá, município de Cuiabá, as folhas são utilizadas na forma de chá e banhos para fraqueza e também para malina (Pasa, 1999).

Ainda em Mato Grosso, na Aldeia Pakueran, em Paranatinga, as folhas são fervidas e utilizadas em banho para febre e "quentura" na cabeça, espécie de enxaqueca (Schimöller, 1997). Em Nova Xavantina, há relatos do emprego do sumo das folhas de negramina misturado com mastruz (Chenopodium ambrosioides) como adjuvante em pós-operatório.

Fontelle (2001) relatou em sua pesquisa as indicações de raizeiros de Cuiabá, que recomendam o uso da folha na forma de decocto e infuso para malina, hipertermia, hemoptise, resfriado e banho de descarrego para mau olhado, podendo para isso ser associada a quina. Além disso, suas folhas são utilizadas em galinheiros como repelente para piolho de galinha e também para uso em rituais espirituais (Duarte, 2001).

Tendo em vista que muitas sociedades tradicionais possuem vasta farmacopéia natural proveniente dos recursos vegetais encontrados nos ambientes naturais (Amorozo, 2002), o objetivo deste estudo foi avaliar o uso de $S$. guianensis por moradores da comunidade ribeirinha de Bom Sucesso, no município de Várzea Grande, Mato Grosso.

\section{Materiais e métodos}

ÁREA DE ESTUDO

A comunidade ribeirinha de Bom Sucesso (15 42'54,23"S e 56 06'21,64"W), um dos distritos do município de Várzea Grande, Mato Grosso, criado por lei em 1948, situa-se às margens do rio Cuiabá, $152 \mathrm{~m}$ metros acima do nível do mar (Figura 1).

O município de Várzea Grande, com extensão territorial de $949,53 \mathrm{~km}^{2}$, faz limites com as Cidades de Cuiabá, Acorizal, Jangada, Santo Antônio do Leverger e Nossa Senhora do Livramento, tendo sido designada como uma região da Depressão Cuiabana (Brasil, 1982).

A estimativa da população de Várzea Grande para 2004 era de 242.674 habitantes e para Bom Sucesso, de 2.757 habitantes, sendo 2.211 na zona rural e 546 na zona urbana (IBGE, 2004).

Do ponto de vista geomorfológico, a região possui a topografia rebaixada em torno de $150 \mathrm{~m}$ a $200 \mathrm{~m}$ de altitude, sendo caracterizada por relevo de planície desenvolvido sobre rochas pré-cambrianas fortemente deformadas (Brasil, 2007).

O clima de Várzea Grande está na categoria Aw da classificação de Köppen, tropical semiúmido, caracterizando-se por apresentar duas estações bem definidas: a seca, de abril a outubro, e a chuvosa, de novembro a março. A pluviosidade média anual da região oscila em torno de $1.350 \mathrm{~mm}$, com sazonalidade marcada por dois períodos bem distintos: na estação chuvosa, verificam-se os maiores índices pluviométricos, oscilando entre $1.000 \mathrm{~mm}$ e $1.500 \mathrm{~mm}$, enquanto na estação seca, a precipitação chega a ser quase nula (INMET, 1996; 1997). A temperatura média anual é de $26^{\circ} \mathrm{C}$, com temperaturas mínimas próximas a $15^{\circ} \mathrm{C}$ em julho e máximas superiores a $32^{\circ} \mathrm{C}$ em outubro. A umidade relativa do ar varia muito, com média anual em torno de 74\% (Brasil, 2007).

O solo é classificado como Argissolo Vermelho-Amarelo distrófico, de textura arenosa/média (Machado et al., 2006). A vegetação é composta por savana arbórea aberta (Cerrado), capoeira e mata ciliar (Oliveira, 2008). 


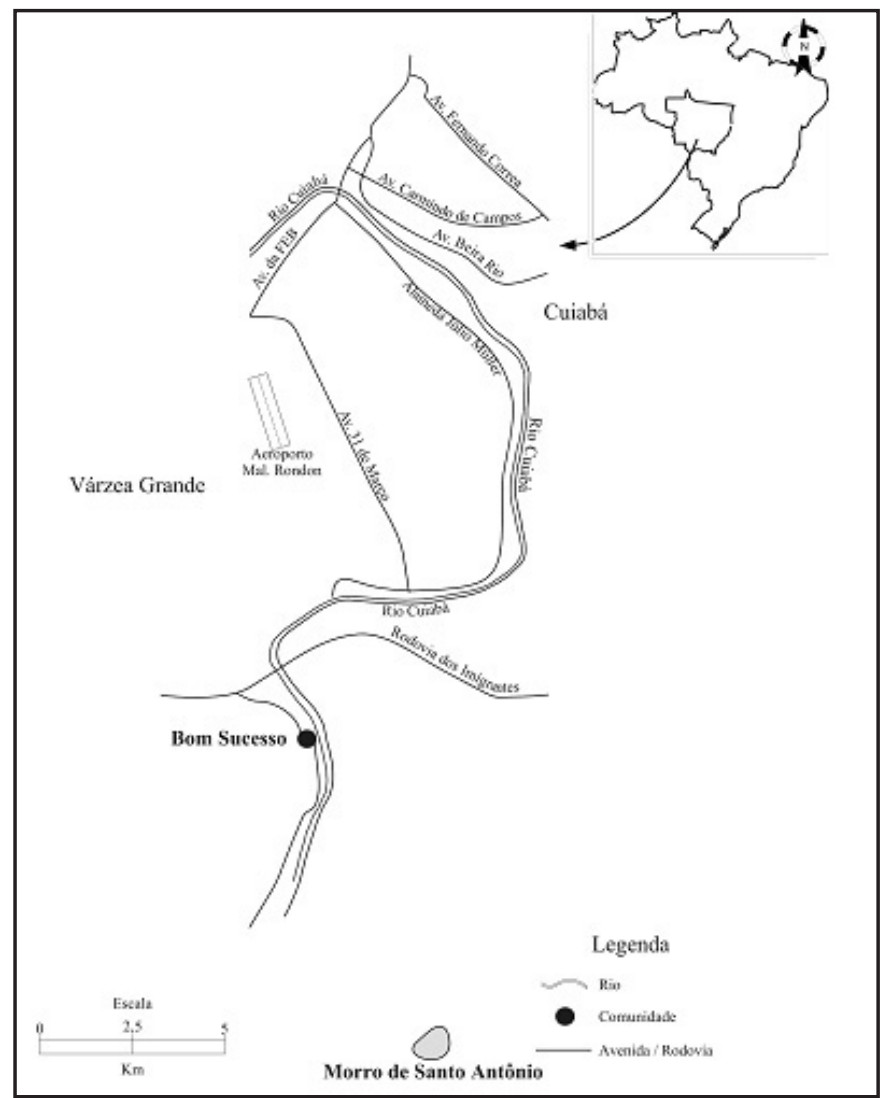

Figura 1 - Localização do distrito de Bom Sucesso, no município de Várzea Grande, Mato Grosso.

Bom Sucesso, a $15 \mathrm{~km}$ do centro de Várzea Grande, é um lugarejo formado por ruas estreitas, cuja rua principal tem mais de um quilômetro de extensão e é paralela ao rio Cuiabá, de onde se podem ver os pescadores em suas estreitas canoas. Essa rua é calçada com blocos de cimento e ladeada por casas, geralmente próximas umas das outras, com poucas cercas ou muros, quintais grandes e arborizados (Campo, 2006).

Atualmente, o distrito tornou-se rota turística, porque nos restaurantes instalados à beira do rio Cuiabá são servidos os peixes da cozinha tradicional, atração turística em toda a região, além das rapaduras ali fabricadas, que também são atrativas para os visitantes.

\section{ColetA DE DADOS}

Os dados foram coletados nos meses de outubro e novembro de 2008, sendo aplicada a técnica de entrevistas semiestruturadas (Albuquerque et al., 2008). As questões, gravadas em fita microcassete (Gravador Olympus mod. Pearlcorder S701), com a per- missão dos entrevistados, compreenderam os aspectos socioeconômicos e culturais, além de conhecimento e uso da negramina. Os participantes foram inicialmente escolhidos ao acaso, por meio de questões fechadas e/ou abertas, e depois intencionalmente, para que se tivesse uma abrangência das diferentes faixas etárias da comunidade, de forma a investigar a transmissão do saber local dos mais velhos para os mais novos.

\section{Resultados e Discussão}

\section{Aspectos SOCIOECONÔMICOS}

Foram entrevistadas 24 pessoas da comunidade, sendo 13 homens e 11 mulheres. Deste total, 20 participantes nasceram e foram criados em Bom Sucesso, dois nasceram em outras comunidades da Várzea Grande, denominados Engordador e Pai André, um em Cáceres, Mato Grosso, e outro em Cuiabá, Mato Grosso. Porém, os participantes que não nasceram no local, foram ali criados ou moram na localidade desde que se casaram. 
Segundo Campo (2006), em Bom Sucesso, a construção da identidade se dá nas relações de acontecimentos passados que são importantes para essas pessoas. Gimènez (2000), por seu turno, afirmou que esta seria a identidade histórica e patrimonial, pois a grande maioria dos moradores é nascida nesses lugares, sendo poucos os "estranhos", como são chamadas as pessoas que não nasceram nas comunidades. Dessa forma, prevalecem os laços de consanguinidade, os quais, aliados a outros fatores, permeiam as práticas sociais e culturais que vêm sendo passadas de geração em geração e que ainda fazem parte da vida dos moradores dessas sociedades.

As idades dos entrevistados variaram entre 15 e 91 anos, com predominância $(29,2 \%)$ da faixa etária de 66 a 75 anos, conforme apresentado na Figura 2.
A maioria dos entrevistados (75\%) estudou apenas no local e mais da metade deles cursou apenas os quatro primeiros anos escolares (Figura 3).

Entre os entrevistados, mesmo os aposentados e as donas de casa ainda trabalham na roça, na criação de animais, na pesca de subsistência, fazendo rapadura e "bicos" nas peixarias do local para ajudar no sustento da família.

CONHECIMENTO, USO, MANEJO E CONSERVAÇÃO DA NEGRAMINA

Do total de participantes, $66,7 \%$ conhecem e usam a negramina, $12,5 \%$ a conhecem mas não fazem mais uso dela, $12,5 \%$ já ouviram falar mas nunca a usaram e $8,3 \%$ nunca ouviram falar desta planta. Constatou-se

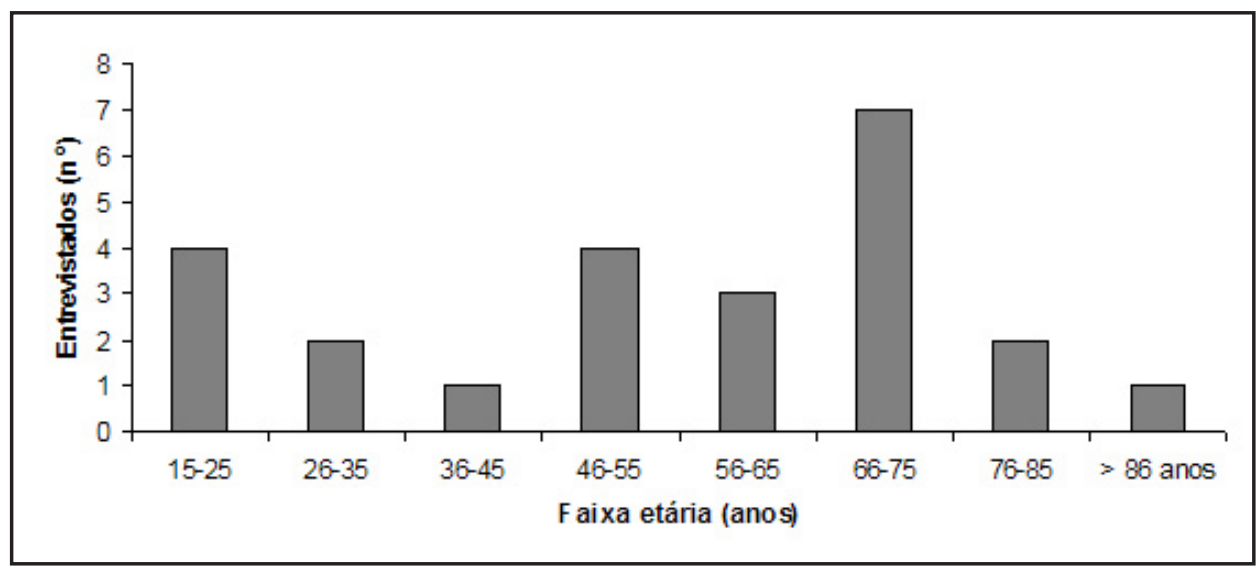

Figura 2 - Faixa etária dos entrevistados em Bom Sucesso, Várzea Grande, Mato Grosso.

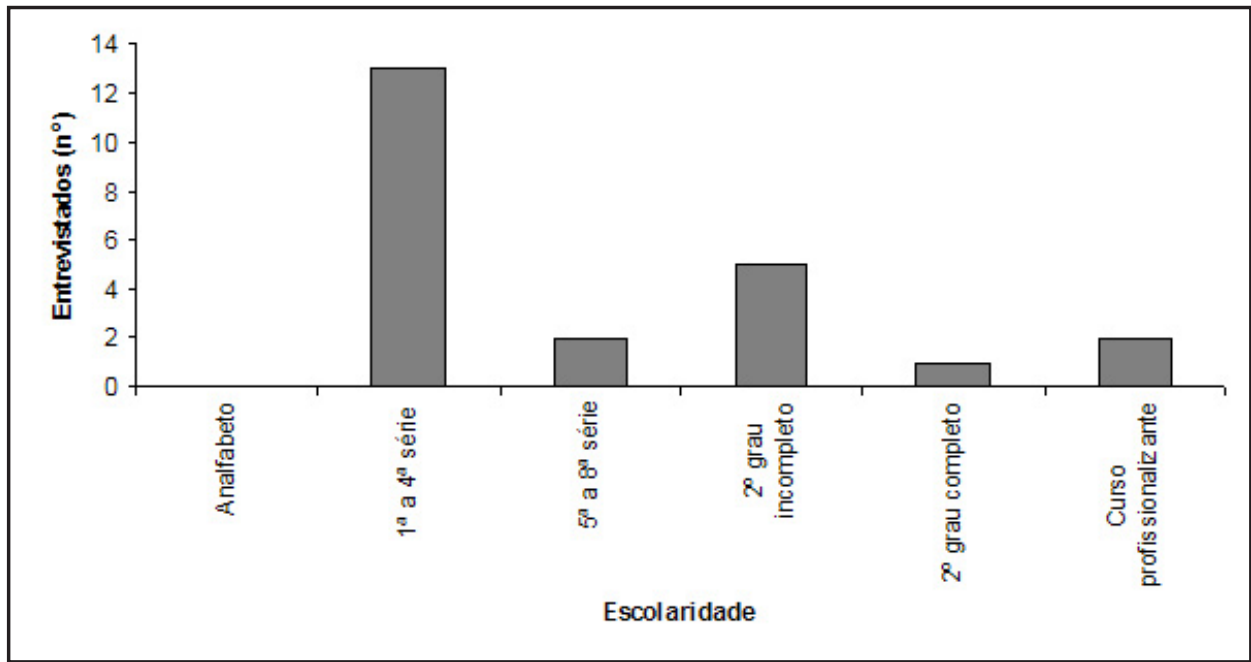

Figura 3 - Nível de escolaridade dos entrevistados em Bom Sucesso, Várzea Grande, Mato Grosso. 
que o conhecimento dos mais velhos sobre a S. guianensis não está sendo assimilado pela geração mais jovem, a qual, em sua maioria, alegou não conhecer e nunca ter usado ou ter abandonado o uso desta espécie.

Todos os entrevistados que fazem ou faziam uso da negramina afirmaram que cozinham as folhas da planta, esperam esfriar e a usam na forma de banho. As indicações de usos medicinais de S. guianensis citadas pelos entrevistados, bem como o número de vezes em que foram citadas, são mostrados na Figura 4.

As citações das enfermidades foram transcritas da forma como foram anotadas a partir das entrevistas. As pessoas que ainda usam a negramina, que são as mais idosas, detentoras das informações passadas de gerações anteriores, assim relataram seu uso:

Remédio assim pra banho, pra criança, pra pessoa que sofria de dor de cabeça, é ideal. Folha e galho pra tomar banho. Pra beber é ruim... ruim, ruim, ruim mesmo... Pra febre, vai sarar. Pra gente que tem quentura na cabeça...

[...] Tradição. A medicina era difícil. O primeiro socorro era o mato, a gente passa... (Seu Painha, 78 anos)
Das pessoas que citaram o banho com negramina, três recomendaram que este fosse tomado à noite e que, logo após, deve-se rebuçar, isto é, se cobrir, e só sair de casa no outro dia.

Minha mãe fazia com nóis... A criança tava com febre, aquela febre que não cortava, aquele que se pegava nele assim, tava com o olho vermelho [...] A mãe fazia o remédio, era esse aí... Fazia o chá de negramina, banho da negramina, mas não podia pegar vento... Porque ele é quente. Dava o banho na criança, enleava ele, guardava ele, dava um Melhoral infantil, Anador. No outro dia, a gurizada tava correndo. Cortava febre, cortava dor, cortava tudo... (Seu José, 54 anos)

Um dos entrevistados recomendou cozinhar as folhas da negramina com erva-debicho (Polygonum hydropiper) e chá de frade (Leonurus sp) para gripe. Outro afirmou que o banho é melhor se as folhas de negramina forem misturadas com erva de bicho, folhas de tamarindo (Tamarindus indica) e folhas de eucalipto (Eucalyptus globulus). Um terceiro ensinou a usar as folhas cozidas com um pouco de sal. Apenas dois disseram que se pode beber o chá, mas que tem sabor ruim.

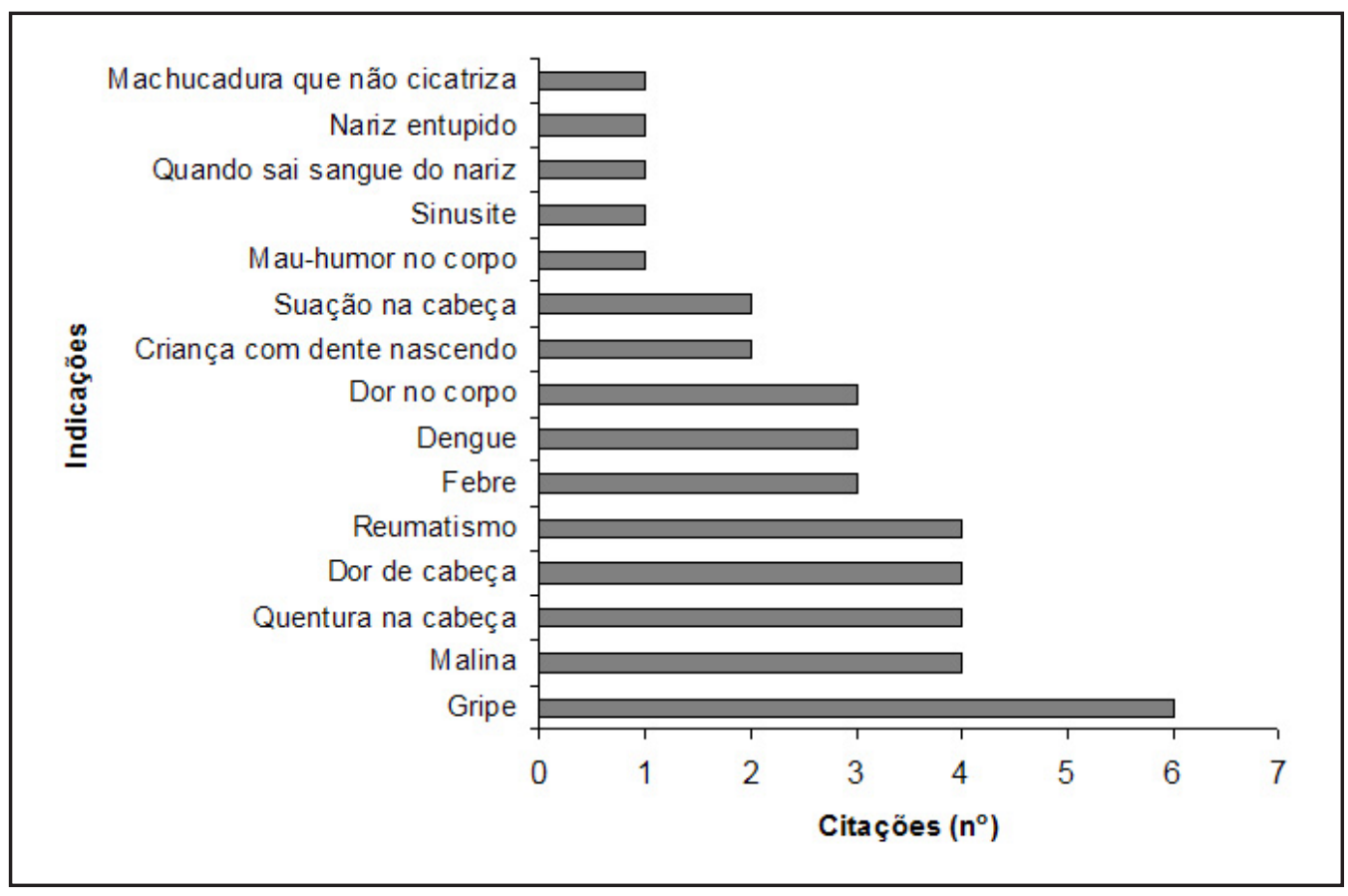

Figura 4 - Usos medicinais da Siparuna guianensis citados pelos entrevistados em Bom Sucesso, Várzea Grande, Mato Grosso. 
Três entrevistados citaram também o uso da casca dos galhos colocada em vinho branco para reumatismo:

Um senhor daqui usa a casca pra pôr no vinho... Diz que é muito bom pra reumatismo.

(Dona Teonila, 78 anos)

Mesmo que não utilizem mais a negramina, alguns entrevistados mantêm viva a memória de seu uso e explicam o que aprenderam com seus pais e avós:

A negramina, antigamente, o pessoal, minha mãe, minha avó [...] em uma machucadura, uma dor de cabeça. Naquela época, quando a criança saía pra brincar e, vamos supor, tinha uma cortadura que tava demorando pra cicatrizar, aí fazia a negramina, cozinhava e lavava com ela e cicatrizava. Minha mãe usava muito pra dor de cabeça. Assim... pegava a negramina, moiava o pano e punha na testa aquele pano moiado e dormia. No outro dia, tava bom. Se especialmente mulher tava com dor de cadeira, dores no corpo, chá de negramina e banho com sal. Deixava esfriar, punha o sal, fazia aquela salmoura com negramina, rebuçava a pessoa. No outro dia, a pessoa suava e a febre ia embora. (Seu José, 54 anos)

A área de coleta pela comunidade era mais acessível antigamente. Embora o rio Cuiabá e além-margem não sejam mostrados como limites do território para a comunidade, uma das justificativas para o abandono do uso desta espécie é a distância que tem de ser percorrida para buscá-la. É unânime nas entrevistas que a negramina só é encontrada do outro lado do rio, próximo ao Morro de Santo Antônio. Assim sendo, necessitam de canoa e ainda têm de andar alguns quilômetros a pé para chegar ao local. Em adição a isso, alguns entrevistados alegam que o local foi loteado e cercado, muitos já estão idosos e dependem de outras pessoas para buscar a planta. Nem sempre há esta disposição dos mais novos, que acham mais fácil comprar um remédio na farmácia.

Reconhecido como patrimônio histórico, cultural e ambiental por lei estadual, o Morro de Santo Antônio (15 45'58,64"S e
56 05'45,50"W) está localizado às margens do rio Cuiabá, a $500 \mathrm{~m}$ do nível do mar, no município de Santo Antônio do Leverger. Em relação a Bom Sucesso, está do outro lado da margem do rio.

Seu Petronilo, mais conhecido como Fião, bisneto do fundador da comunidade, deu uma descrição de como conheceram o local de coleta e como ele era no passado:

A gente campeava. A gente tinha umas criação... Na oportunidade de campear é que a gente conheceu esse lugar... Tinha uma comunidadezinha por nome Guanami, que fica logo pertinho lá, pertinho desse córgo. Travessa o córgo Cascavel, já logo tá chegando pertinho do Guanami. Era uma comunidade de quatro a cinco moradores... Hoje, lá eles venderam, é uma fazendinha lá... Dá pra chegar de a pé, de cavalo. Hoje lá já ficou o local, já é fundo do loteamento da Cachoeira de Pólvora. Por aqui, parece 2 horas, distância quase daqui na Várzea Grande.

Os moradores relataram encontrar a planta perto de um córrego e em campo aberto, mas não na beira do rio. A seguir, o depoimento de uma participante sobre o local onde a espécie é encontrada, deixando claro que fica do outro lado do rio, próximo do Morro de Santo Antônio:

Óia, nóis pegava lá do outro lado do rio,
mas agora faz muito tempo que não pego
[...] Ficou difícil. Venderam pra lá. Ficou
tudo loteado, cercaram [...] Óia, num sei.
Faz muitos anos que não vou pro outro
lado [...] É pranta de campo. Ele nasce na
terra do campo, não nasce na beira do rio...
Atravessa de canoa e anda um pedação...
(Dona Lucinda,68 anos)

Sobre a época de coleta, três entrevistados relataram a antiga tradição de pegar a negramina na Semana Santa para o ano inteiro, dois garantiram que a coleta pode ser feita em qualquer época depois da brotação e os demais, em qualquer época do ano. Como apenas quatro entrevistados afirmaram conhecer a flor da espécie e apenas dois, o fruto, supôs-se que fazem a coleta da negramina em seu estágio vegetativo. Vale salientar que, pelo 
acompanhamento da fenologia da espécie em Cuiabá, a semana da Páscoa coincide com o período vegetativo da espécie, após a queda de frutos, que ocorre entre fevereiro e março.

Costume... Nóis saía quinta-feira meianoite e ia amanhecer lá na Sexta-feira Maior em cima do morro. E de dia, vinha embora... Nesta data é que dá de nóis ir lá... Então, lá tem muito remédio... remédio de todo tipo lá... Nóis pega nesse dia lá e nóis guarda e ela seca...

(Seu Davi, 58 anos)

Cabe ressaltar que na época da Semana Santa, os principais componentes encontrados por Valentini (2009) no óleo essencial das folhas da espécie foram: siparunona (59,5\%), veridiflorol $(7,2 \%)$, ledol $(7,14 \%)$, espatulenol $(6,80 \%)$ e 2 -undecanona $(1,05 \%)$. Os compostos ledol, espatulenol e veridiflorol também foram encontrados em estudos de própolis brasileira (Bankova et al., 1995; Bankova et al., 1998; Bankova et al., 1999; Sousa et al.,2006), lembrando que esta tem atividade antibacteriana, antiviral, fungicida, antiinflamatória, oxidante e antitumoral (Russo et al., 2004), entre outras.

Com relação à quantidade de plantas da espécie no local de origem, houve contradição entre os entrevistados, pois alguns achavam que a quantidade diminuiu, principalmente em decorrência das queimadas, enquanto outros opinaram que o local permanece preservado. Entre estes últimos, foi unânime o relato de que a negramina rebrota depois da chuva, uma vez que asseguraram que o fogo não atinge a raiz da espécie. A seguir, são apresentados alguns depoimentos sobre a época em que os moradores da comunidade vão buscá-la e como está o local de coleta:

A quantidade de negramina, diminuiu. Estão desmatando...

(Seu Painha, 78 anos)

Mas agora tá difícil, por causa da desordem dos fogo. Tacação de fogo queimou tudo... Só depois que chovê é que ela vai brotar... A raiz, ela rebrota... É planta nativa... Não diminuiu a quantidade... Ela brota. Basta começá chovê...

(Dona Teonila, 75 anos)
Sobre o fato de passarem a negramina para pessoas de fora da comunidade, apenas dois entrevistados citaram que há encomendas da planta:

As criança vai lá panhá... Encomenda pra Souza Lima, Cuiabá... Pega feixe dele e o pessoal vem buscá... Até do Santo Antônio vem buscá... Sempre pessoal de Souza Lima encomenda pra nóis...

(Seu Cirilo, 73 anos)

Além de não conhecerem a $S$. guianensis em seu estado reprodutivo, os entrevistados nunca fizeram tentativas de propagá-la, o que não pode ser interpretado como um descaso com a espécie. Diegues (2003) afirmou que para as sociedades tradicionais, diferentemente das sociedades urbanas, o território é descontínuo (áreas de pousio, áreas de pesca usadas em apenas parte do ano), ou seja, há um sistema de manejo de recursos naturais marcado pelo respeito aos ciclos naturais, bem como à exploração dentro da capacidade de recuperação das espécies de animais e plantas utilizadas. Este pensamento ficou bem expresso na frase de Seu Painha, de 78 anos:

Onde tem fartura pra panhá, ninguém planta...

Pôde-se observar que entre os entrevistados mais jovens, alguns já tinham ouvido falar da negramina, embora tenham afirmado não possuir informações acerca de seu uso, enquanto outros nunca ouviram falar da espécie, o que nos leva a uma reflexão sobre a possibilidade de o saber local estar se perdendo nas novas gerações. Outros estudos com comunidades tradicionais, como o de Amorozo (2002), que pesquisou três comunidades rurais de Santo Antônio do Leverger, Mato Grosso, também concluíram que a "modernização" traz consigo novas opções de cuidados com a saúde, enquanto ocorre certa desvalorização da cultura local. Como os jovens são mais sensíveis às mudanças, têm maior tendência à perda ou ao abandono das práticas tradicionais.

Estudando o conhecimento tradicional em uma comunidade na Amazônia, Shanley \& Rosa (2005) observaram que, apesar de muitos capimenses (pessoas da região do rio Capim) conhecerem a utilidade de muitas 
espécies de plantas, o uso ativo de algumas delas tem declinado. Isto foi demonstrado por meio de afirmações frequentes de que as avós usavam tais recursos, mas eles não os empregam mais.

Particularmente para fins tecnológicos e alguns medicinais, existem muitos usos de plantas, principalmente na memória das pessoas, sendo questionável se a identificação das espécies, os regimes de coleta e as técnicas de processamento podem sobreviver mais do que poucas gerações, uma vez que deixem de ser praticados.

Para Fleury \& Almeida (2007), deve-se também considerar que as populações tradicionais não são exclusivamente aquelas que mantêm padrões imutáveis ao logo dos anos. Pelo contrário, seria justamente na adaptação aos novos contextos, sem ferir seus valores tradicionais, que estaria a sua sustentabilidade.

Essa transformação pode ser observada na comunidade de Bom Sucesso, que mesmo mantendo muitos dos seus costumes, também se caracteriza por uma situação socioeconômica em transformação. Há o confronto entre modos de pensar e agir tradicionais e novas ideias e costumes trazidos com o contato intensificado em décadas recentes com a sociedade nacional, que se reflete também nas questões ligadas à saúde e à doença. Essa ideia foi traduzida nas palavras de Seu José, de 54 anos:

Olha, hoje não busca mais a negramina, você sabe... Tá tudo moderno... Qualquer coisinha, já é médico. O pessoal já abandonaram esse lado...

Portanto, as formas de manejo dos recursos naturais das comunidades tradicionais, suas formações simbólicas, suas práticas culturais e suas técnicas tradicionais, que representam o saber de várias gerações que vivem da e para a natureza (Pasa, 2007), precisam ser documentadas para que as referências históricas dessas comunidades não se percam para as novas gerações.

\section{Conclusão}

A principal forma de uso de S. guianensis, conhecida como negramina, é a decocção de suas folhas para uso na forma de banho tópico, especialmente para gripe, febre e dor no corpo. O conhecimento do uso medicinal desta espécie não está sendo passado às novas gerações.

\section{RefERÊNCIAS}

Albuquerque, U. P. A., R. F. P. Lucena \& L. V. F. C. Cunha, (Orgs). 2008. Métodos e técnicas na pesquisa etnobotânica. $2^{a}$ ed., NUPPEA, Recife, 323 p.

Amorozo, M. C. M. 2002. Uso e diversidade de plantas medicinais em Santo Antonio do Leverger, MT. Acta Bot. Bras. 16(2): 189-203.

Arjona, F. B. S., R. C. M. Montezuma \& I. M. Silva. 2007. Aspectos etnobotânicos e biogeografia de espécies medicinais e/ou rituais comercializadas no mercado de Madureira, RJ. Cam. Geograf. 8(23): 4150.

Bankova, V. S., R. S. Christov, A. DelgadoTejera. 1998. Lignans and other constituents of propolis from the Canary Islands. Phytochemistry 49(5): 1411-1415.

Bankova, V. S., R. S. Christov, A. Kujiumgiev, M. C. Marcucci \& S. Popov. 1995. Chemical composition and antibacterial activity of Brazilian propolis. Z. Naturforsch. C 50: 167-172.

Bankova, V. S., R. S. Christov, S. Popov, M. C. Marcucci, I. Tsvetkova \& A. Kujumgiev. 1999. Antibacterial activity of essential oils from Brazilian propolis. Fitoterapia, 70(2): 190-193.

Bourdy, G., S. J. DeWalt, L. R. Chávez de Michel, A. Roca, E. Deharo, V. Muñoz, L. Balderrama, C. Quenevo \& A. Gimenez. 2000. Medicinal plants uses of the Tacana, an Amazonian Bolivian ethnic group. J. Ethnopharmacol. 70(2): 87-109.

Brasil. 1982. Ministério das Minas e Energia. Projeto RADAMBRASIL. Rio de Janeiro, 544 p. (Levantamento de Recursos Naturais, 26).

Brasil. 2007. Fundação Nacional de Saúde do Ministério da Saúde. Cemitérios como fonte potencial de contaminação das águas subterrâneas. Região de Cuiabá e Várzea Grande (MT). Relatório final. 
Brasília, 118 p. Disponível em <http:// www.funasa.gov.br/internet/arquivos/ biblioteca/cemitFonte.pdf $>$. Acesso em: 30 de novembro de 2008.

Campo, L. M. C. 2006. A paisagem simbólica de Bom Sucesso e Limpo Grande, em Várzea Grande - MT. Dissertação de Mestrado, Instituto de Ciências Humanas e Sociais, Universidade Federal de Mato Grosso, Cuiabá.

Carmona, P. F. \& G. Guarim Neto. 2001. As plantas medicinais, suas formas de uso e aplicabilidade fitoterápica: o saber tradicional. In: Universidade Federal do Mato Grosso. Uso da biodiversidade: flora medicinal do cerrado do leste matogrossense: uma abordagem etnobotânica. Cuiabá, Instituto de Biociências, Departamento de Botânica e Ecologia. (Relatório técnico).

Christo, A. G., R. R. Guedes-Bruni \& V.S. Fonseca-Kruel. 2006. Uso de recursos vegetais em comunidades rurais limítrofes à Reserva Biológica de Poço das Antas, Silva Jardim, Rio de Janeiro: estudo de caso na Gleba Aldeia Velha. Rodriguésia 57(3): 519-542. Disponível em: <http://rodriguesia.jbrj.gov.br/rodrig57_3/10Christo. pdf $>$. Acesso em: 12 jan. 2008.

Diegues, A. C. 2003. O mito moderno da natureza intocada. $3^{a}$ ed., Hucitec, São Paulo, $169 \mathrm{p}$.

Duarte, T. G. 2001. Um estudo etnoecológico sobre o uso de recursos vegetais em Nova Xavantina, Mato Grosso. Dissertação de Mestrado. Instituto de Biociências, Universidade Federal de Mato Grosso, Cuiabá.

Fleury, L. C. \& J. Almeida. 2007. Populações tradicionais e conservação ambiental: uma contribuição da teoria social. Rev. Bras. Agroecol. 2(3): 3-19. Disponível em: <http://www6.ufrgs.br/pgdr/arquivos/ 542.pdf>. Acesso em: 20 jan. 2008.

Fontelle, M. G. L. C. 1997. Plantas medicinais utilizadas por raizeiros: uma abordagem etnobotânica no conteúdo da saúde e da doença. Dissertação de Mestrado. Instituto de Biociências, Universidade Federal de Mato Grosso, Cuiabá.
Gimènez, G. 2000. Território, cultura e identidades. La región sociocultural, p. 87132. In: J. M. Barrero, F. L. Roche \& A. Robledo (Eds), Cultura y región. Bogotá, Ces/Universidad Nacional/Ministerio de Cultura.

IBGE. Fundação Instituto Brasileiro de Geografia e Estatística. 2004. Estimativas de população. Disponível em: <http:// www.ibge.gov.br/home/presidencia/noticias/27072004estimativas2004. shtm>. Acesso em: 30 de novembro de 2008.

INMET. Instituto Nacional de Meteorologia do Ministério da Agricultura. 1996. Boletim Agroclimatológico. Brasília, v. 30, n. 1-12.

INMET. Instituto Nacional de Meteorologia do Ministério da Agricultura. 1997. Boletim Agroclimatológico. Brasília, v. 31, n. 1-12.

Lorenzi, H. \& F. J. A. Matos. 2002. Plantas medicinais no Brasil: nativas e exóticas. Nova Odessa, Instituto Plantarum, 512 p.

Machado, A. Q., A. M. G. Romio \& G. S. Chitarra. 2006. Seleção de cultivares de tomate para plantio em Várzea GrandeMT. In: $46^{\circ}$ Congresso Nacional de Olericultura, Goiânia. Resumos, p. 1025-1028. Disponível em <http://www.abhorticultura.com.br/biblioteca / arquivos / Download/Biblioteca/46_0256.pdf>. Acesso em: 24 jan. 2008.

Milliken, W. \& B. Albert. 1996. The use of medicinal plants by the Yanomamy Indians of Brazil. Econ. Bot. 50(1): 10-25.

Monteles, R. \& C. U. B. Pinheiro. 2007. Plantas medicinais em um quilombo maranhense: uma perspectiva etnobotânica. Rev. Biol. Ciênc. Terra 7(2): 38-48. Disponível em: <http://eduep.uepb.edu. $\mathrm{br} / \mathrm{rbct} /$ sumarios/pdf/etnobotanica. pdf>. Acesso em: 15 maio 2008.

Nordi, N., A. P. G. Thé \& J. S. Mourão. 2001. Etnoecologia, educação ambiental e desenvolvimento sustentável, p. 133-144. In: J. E. Santos \& M. Sato (Orgs), A contribuição da educação ambiental à esperança de Pandora. São Carlos, RIMA. 
Oliveira, A. G. 2008. Avaliação das temperaturas superficiais do solo em relação à conformação urbana existente na Praça do Aeroporto Marechal Rondon em Várzea Grande/MT. Dissertação de Mestrado, Instituto de Ciências Exatas e da Terra, Universidade Federal de Mato Grosso, Cuiabá. Disponível em: $<$ http://pgfa.ufmt.br/pagina/index. php?option=com_docman\&task=cat_vie w\&gid=15\&dir=DESC\&order=date\&Ite mid $=37 \&$ limit $=10 \&$ limitstart $=30>$. Acesso em: 10 maio 2008.

Pasa, M. C. 1999. A utilização dos recursos vegetais no Vale do Aricá, Mato Grosso: um estudo etnoecológico. Dissertação de Mestrado. Instituto de Biociências, Universidade Federal de Mato Grosso, Cuiabá.

Pasa, M. C. 2007. Um olhar etnobotânico sobre as comunidades do Bambá, CuiabáMT. Editora da UFMT, Cuiabá, 143 p.

Pinto Sobrinho, F. A. 2007. Conhecimento etnobotânico de mateiros residentes no entorno de Unidades de Conservação no estado do Rio de Janeiro. Dissertação de Mestrado. Escola Nacional de Botânica Tropical, Instituto de Pesquisas Jardim Botânico do Rio de Janeiro, Rio de Janeiro.

Prance, G. T. 1972. Ethnobotanical notes from Amazonian Brazil. Econ. Bot. 26(3): 221237.

Renner, S. S. \& G. Hausner. 2005. Monograph of Siparunaceae. Flora Neotrop. 95: 1-256.

Rocha-Coelho, F. B. \& M. G. Santos. 2007. Plantas medicinais utilizadas pela $\mathrm{CO}^{-}$ munidade Mumbuca Jalapão - TO: um estudo etnofarmacológico. Pesquisa e Conservação do Cerrado. Disponível em: $<$ http://www.pequi.org.br/Coelho_\&_ Santos.pdf>. Acesso em: 5 maio 2008.

Rodrigues, L. A, D. A. Carvalho, L. J. Gomes \& R. T. Botrel. 2002. Espécies vegetais nativas usadas pela população local em Luminárias-MG. Bol. Agropec. 52: 1-34. Disponível em: <http://www.editora. ufla.br/BolTecnico/pdf/bol_52.pdf>. Acesso em: 13 jun. 2008.
Rodrigues, V. E. G. \& D. A. Carvalho. 2001. Levantamento etnobotânico de plantas medicinais no domínio do cerrado na região do Alto Rio Grande - Minas Gerais. Ciênc. Agrotecnol. 25(1): 102-123. Disponível em: <http://www.agencia. cnptia.embrapa.br/recursos /FLO_Etnob_Cerrado_MGID-0zWHltLEGY.pdf > . Acesso em: 10 maio 2008.

Russo A., V. Cardile, F. Sanchez, N. Troncoso, A. Vanella \& J. A. Garbarino. 2004. Chilean propolis: antioxidant activity and antiproliferative action in human tumor cells lines. Life Sci. 76(5): 545-558.

Santos, I. S. \& A. L. Peixoto. 2001. Taxonomia do gênero Macropeplus Perkins (Monimiaceae, Monimioideae). Rodriguésia 52(81): 65-105. Disponível em: <http://rodriguesia.jbrj.gov.br/Rodrig52_81/5-santos. pdf $>$. Acesso em: 3 fev. 2008.

Schimöller, E. 1997. Levantamento preliminar das plantas medicinais utilizadas pelos índios Bakairi, Aldeia Pakueran (Paranatinga, Mato Grosso). Trabalho de Conclusão de Graduação. Instituto de Biociências, Universidade Federal de Mato Grosso, Cuiabá.

Shanley, P. \& N. A. Rosa. 2005. Conhecimento em erosão: um inventário etnobotânico na fronteira de exploração da Amazônia Oriental. Bol. Mus. Pará Emílio Goeldi, Série Ciências Naturais, 1(1): 147-171. Disponível em: <http:/ /scielo.iec.pa.gov. $\mathrm{br} / \mathrm{pdf} / \mathrm{bmpegscn} / \mathrm{v} 1 \mathrm{n} 1 / \mathrm{v} 1 \mathrm{n} 1 \mathrm{a} 09 . \mathrm{pdf}>$. Acesso em: 2 jun. 2008.

Somavilla, N. V. 1998. Utilização de plantas medicinais por uma comunidade garimpeira do sudeste mato-grossense, Alto Coité - Poxoréo, Mato Grosso. Dissertação de Mestrado. Instituto de Saúde Coletiva, Universidade Federal de Mato Grosso, Cuiabá.

Sousa, S. A. A., A. M. G. L. Citó \& J. A. D. Lopes. 2006. Constituintes do óleo essencial da própolis produzida na cidade de Pio IX - Piauí. Rev. Bras. Plantas Med. 8(4): 1-3. Disponível em: <http://www.ibb. unesp.br/servicos/publicacoes/rbpm/ pdf_v8_n4_2006/artigo1_v8_n4_p001003.pdf $>$. Acesso em: 9 jun. 2008. 
Souza, C. D. \& J. M. Felfili. 2006. Uso de plantas medicinais na região de Alto Paraíso de Goiás, GO, Brasil. Acta Bot. Bras. 20(1) 135-142. Disponível em: <http://www. scielo.br/pdf/abb/v20n1/13.pdf $>$. Acesso em: 22 jun. 2008.

Souza, L. F. 1992. Levantamento etnobotânico na localidade de São Gonçalo, Cuiabá, Mato Grosso, Brasil. Trabalho de Conclusão de Graduação. Instituto de Biociências, Universidade Federal de Mato Grosso, Cuiabá.
Valentini, C. M. A. 2009. Aspectos etnobotânicos, fenológicos, agronômicos e químicos da Siparuna guianensis Aublet no cerrado de Mato Grosso. Tese de Doutorado. Universidade Federal de Mato Grosso, Cuiabá.

Vigneron, M., X. Deparis, E. Deharo \& G. Bourdy. 2005. Antimalarial remedies in French Guiana: a knowledge attitudes and practices study. J. Ethnopharmacol. 98(3): 351-360. 